\title{
RENAL CELL CARCINOMA IN CHILDHOOD
}

\author{
LUCIANO R. BARROS, SIDNEY GLINA, LUIZ F. MELLO
}

Section of Urology, Ipiranga Hospital, São Paulo, SP, Brazil

\begin{abstract} in children.

The renal cell carcinoma (RCC) rarely occurs in childhood. We report here 3 cases of RCC

Two girls and 1 boy aged 14, 8 and 13 years old, respectively, presented with gross hematuria as their main complaint. They underwent ultrasonography and computerized tomography, which revealed unilateral renal tumor with lymph nodal involvement in all 3 cases. They were treated with radical nephrectomy associated with regional lymphadenectomy, with histopathology of RCC. Incomplete adjuvant radiotherapy was performed in 2 cases and no complementary treatment in the other one. All are disease-free in a period ranging from 9 to 77 months after diagnosis.

Radical nephrectomy associated with regional lymphadenectomy is the best treatment for RCC in childhood. The disease appears to have a less aggressive behavior in children.
\end{abstract}

Key words: kidney neoplasms; children; carcinoma, renal cell; nephrectomy

Int Braz J Urol. 2004; 30: 227-9

\section{INTRODUCTION}

The incidence of renal cell carcinoma (RCC) is estimated in $0.1 \%$ to $0.3 \%$ of all tumors and $1.8 \%$ to $6.3 \%$ of all malignant renal tumors in childhood (1).

No proper therapy has been defined for children with RCC. Surgery constitutes the main treatment and results in cure when the tumor is localized and completely resected. The importance of radiotherapy and immunotherapy is not clear and different chemotherapy regimens showed only minimal activity when tested in clinical trials (1).

The authors report 3 cases of RCC in childhood.

\section{CASE REPORTS}

\section{Case 1}

Fourteen year-old girl was seen in June 1997 with left renal colic and hematuria for 3 months. The ultrasound (US) revealed a nodule in the upper pole of the left kidney, measuring $4.3 \times 4.0 \mathrm{~cm}$, with enlarged perihilar lymph nodes. The computerized tomography (CT) confirmed the findings. She underwent radical nephrectomy with regional lymphadenectomy in July 1997 with histopathological diagnosis of RCC in left kidney and lymph nodes involvement (4/4). The service of oncology initially indicated radiotherapy, which was terminated after the fourth session. The patient has been semestrally followed by US or CT and is disease-free.

\section{Case 2}

Eight years old girl was seen in November 2000 with hematuria for 30 days. A cystoscopy was performed with clot evacuation. The CT revealed a mass in lower pole of the right kidney with ureterohydronephrosis. She underwent radical nephrectomy with regional lymphadenectomy in December 2000, with histopathological diagnosis of RCC in right kidney with capsular infiltration and the presence of 2 
involved hilar lymph nodes. Radiotherapy was initially indicated by the oncology service, and terminated after the first session. She is disease-free.

\section{Case 3}

Thirteen years old boy, seen in February 2003 with hematuria for 8 months, hemoglobin of $9.3 \mathrm{mg} /$ $\mathrm{dL}$ and US performed 30 days before, showed a right renal tumor, which was confirmed by CT (Figure-1). He underwent radical nephrectomy with regional lymphadenectomy (Figure-2) in March 2003, with histopathological diagnosis of RCC in right kidney, with predominance of papillary variant, with lymph node metastasis. He did not undergo any adjuvant therapy and is disease-free.

\section{DISCUSSION}

Recent studies showed that the RCC corresponds to $1.4 \%$ of renal tumors in patients under 4 years old, $15.2 \%$ between 5 and 9 years and $52.6 \%$ from 10 to 15 years old (2).

Palpable mass occurs in $38 \%$, hematuria in $38 \%$ and abdominal pain in $50 \%$, with the classic triad being found in only $6 \%$ of cases (3). Metastases occur in lungs $(40-65 \%)$, liver $(35-57 \%)$, bones $(10-$ $42 \%)$ or bladder, brain or pleura (7-15\%) (2). Surgery constitutes the main treatment (1).

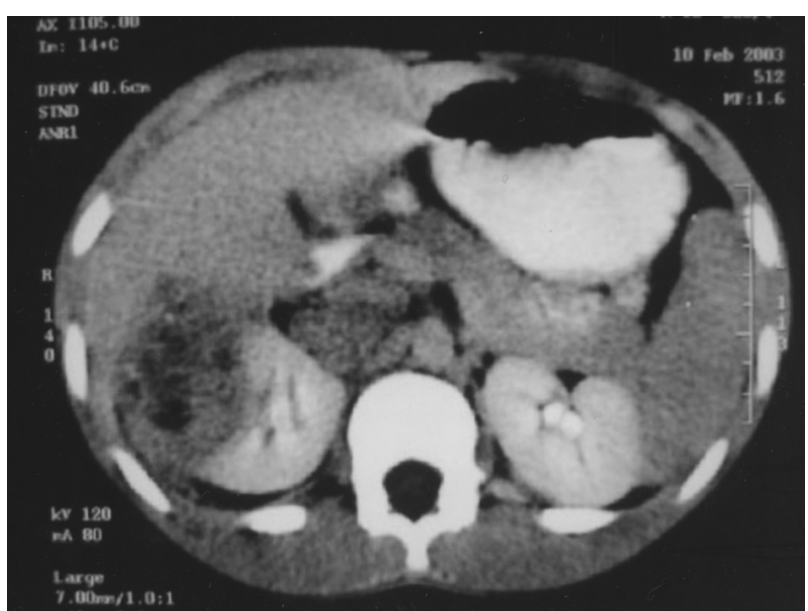

Figure 1 - Computerized tomography evidencing right renal tumor.

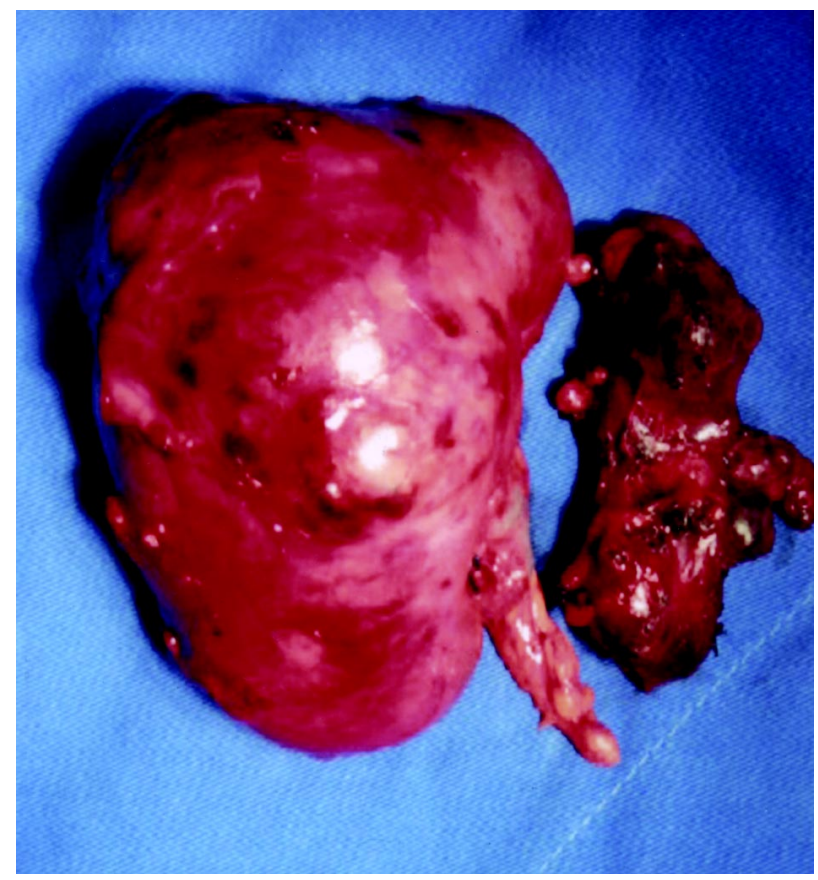

Figure 2 - Surgical specimen from right radical nephrectomy and regional lymphadenectomy.

Tumor staging is the most important prognostic factor. Overall 5-year survival is approximately $60 \%$, with poor prognosis (9\%) for stage IV (2).

Two of our patients started adjuvant radiotherapy. Since we did not find in the literature any incentive for such procedure, we decided jointly with the service of oncology to terminate it. Considering this fact and the good survival we achieved, we can agree with the unanimous opinion expressed in the works we reviewed, that radical nephrectomy associated with regional lymphadenectomy is the best treatment for RCC in childhood. Our results also suggest a less aggressive behavior of the disease in this age range.

\section{REFERENCES}

1. Indolfi P, Terenziani M, Casale F, Carli M, Bisogno G, Schiavetti A, et al.: Renal cell carcinoma in children: A clinicopathologic study. J Clin Oncol. 2003; 21: 5305.

2. Uchiyama M, Iwafuchi M, Yagi M, Inuma Y, Masahiro O, Tomita Y, et al.: Treatment of childhood renal cell carcinoma with lymph node metastasis: Two cases and a review of literature. J Surg Oncol. 2000; 75: 266-9. 
3. Carcao MD, Taylor GP, Greenberg ML, Bernstein ML, Champagne M, Hershon L, et al.: Renal cell carcinoma

Correspondence address:

Dr. Luciano da Rocha Barros

Rua do Arraial, 209 / 24B

São Paulo, SP, 04122-030, Brazil

Fax: + $55116169-9629$

E-mail: lucianobarros@terra.com.br

\section{EDITORIAL COMMENT}

The authors present 3 interesting cases of a rare pediatric tumor, that is renal cell carcinoma. Since the treatment with radiation therapy is not the standard of care, I do not know why they treated their patients with this therapy.

The authors say that the tumor has good prognosis in children, and I do not believe this is what the literature says. Also, they cannot base their conclusion on their limited experience with a short term follow up in children: A different disorder from its adult counterpart? Med Pediatr Oncol. 1998; 31:153-8.

Received: December 12, 2003

Accepted after revision: April 4, 2004 (the authors stated that because one of their patients had advanced disease and is alive, this point to better prognosis in children). It is important to note that most patients with renal cell carcinoma do not have positive nodes, and that in the present series the incidence was higher than expected (even though again it is a limited experience). Also, it is important to remember that lymph node disease is known to significantly worsen the survival of patients with renal cell carcinoma.
Dr. E. Tavora Fernandes Chief of Urology Department of Veterans Affairs Minneapolis, Minnesota, USA 